\title{
Implementation of Modified Best Candidate Method in Fuzzy Assignment Problem
}

\author{
${ }^{1}$ M.Maragatham \\ ${ }^{1}$ Associate Professor of Mathematics, PG and Research Department of Mathematics, Periyar \\ E.V.R College (Autonomous)*, Tiruchirappalli, \\ *Affiliated to Bharathidasan University
}

${ }^{2}$ Suzane Raj. L

${ }^{2}$ Research Scholar,

$P G$ and Research Department of Mathematics, Periyar E.V.R College (Autonomous)*Tiruchirappalli, *Affiliated to Bharathidasan University

\begin{abstract}
To meet the demands of every customer by supplying the products at the limited time by maximizing the profit is a dream for many companies. By choosing the best candidate among the other candidates and effectively reaching the optimal solution with a new modified approach using Best Candidate Method in Fuzzy assignment problems. In this paper the author solve Fuzzy assignment problem in which Triangular and Trapezoidal fuzzy numbers are used. Robust Ranking Technique is used for the ranking of fuzzy numbers.
\end{abstract}

Keywords-Triangular fuzzy Number, Trapezoidal Fuzzy Number, Robust Ranking method.

\section{Introduction}

An assignment problem is a special type of linear programming problem which deals with assigning various activities (jobs or task or sources) to an equal number of service facilities (men, machine, laborers, etc.) on one to one basis in such a way so that the total time or total cost involved is minimized and total sale or total profit is maximized or the total satisfaction of the group is maximized. Ladeh[1] introduced Fuzzy sets and basic concepts of fuzzy theory.[5]The author used Robust's Ranking technique to defuzzify the FAP and optimal solution is found by Using Ones Assignment problem.[8]In 2012 Hlayel introduced a new method, Best Candidate Method (BCM) of electing the candidates among the other and finding the solution for the optimization problems. [7]Furthermore with slight modifications Hlayel extended the method and proposed Modified Best Candidate method [9] In 2016, BCM was implemented to solve Fuzzy Assignment Problems. The coefficients of FAP problems are assumed to be exactly known. In practice, the coefficients (some or all) are not exact due to the errors of measurement or vary with market conditions, so ranking of fuzzy numbers where used. In this paper, the proposed the fuzzy assignment problem FAP is solve by the Modified Best Candidate method using the ranking function for fuzzy costs. An illustrative example is given for the sake of illustration. 


\section{PRELIMINARIES}

\section{A.Fuzzy Sets:}

If $\mathrm{X}$ is a collection of objects denoted generically by $\mathrm{x}$, then the fuzzy set $\mathrm{A}$ in $\mathrm{X}$ is a set of ordered pairs $\tilde{A}=\left\{\left(x, \mu_{\tilde{A}}(x)\right), \mid x \in X\right\}$ is called the membership function of $\mathrm{x}$ in $\mathrm{A}$ that maps $\mathrm{X}$ to the membership space $\mathrm{M}$ (When $\mathrm{M}$ contains only the two points 0 and $1, \tilde{A}$ is non fuzzy and $\mu_{\tilde{A}}(x)$ is identical to the characteristic function of a nonfuzzy set). The range of the membership function is a subset of the nonnegative real numbers whose supremum is finite.

B Normal Fuzzy Set:

A fuzzy set $A$ of the universe of discourse $X$ is called a normal fuzzy set implying that there exist at least one $\mathrm{x} \varepsilon \mathrm{X}$ such that $\mu \mathrm{A}(\mathrm{x})=1$.

C. $\alpha-$ cut :

The $\alpha$ Cut of a $\alpha$ level set of a fuzzy set $\tilde{A}$ is a set consisting of those elements of the universe $\mathrm{X}$ whose membership values exceed the threshold level $\alpha$

$$
\tilde{A}_{\alpha}=\left\{x \mid \mu_{\tilde{A}}(x) \geq \alpha\right.
$$

\section{Triangular Fuzzy Number:}

For a triangular fuzzy number $\mathrm{A}(\mathrm{x})$, it can be represented by $\mathrm{A}(\mathrm{a}, \mathrm{b}, \mathrm{c} ; 1)$ with membership function $\mu(\mathrm{x})$ given by

where $\mathrm{a} \leq \mathrm{b} \leq \mathrm{c}$

$$
\mu(x)=\left\{\begin{array}{cc}
\frac{(x-a)}{(b-a)}, & a \leq x \leq b \\
\frac{(c-x)}{(c-b)}, & b \leq x \leq c \\
0 & \text { otherwise }
\end{array}\right.
$$

The interval of confidence for the triangular fuzzy number $\tilde{A}(a, b, c)$ at $\alpha-$ level set is defined as :

$$
A_{\alpha}=\left(a_{L}^{\alpha}, a_{R}^{\alpha}\right)=[a+(b-a) \alpha, c-(c-b) \alpha], \forall \alpha \in[0,1]
$$

\section{E. Trapezoidal Fuzzy Number:}

For a trapezoidal fuzzy number $\mathrm{A}(\mathrm{x})$, it can be represented by $\mathrm{A}(\mathrm{a}, \mathrm{b}, \mathrm{c}, \mathrm{d} ; 1)$ with membership function $\mu(\mathrm{x})$ given by

where $\mathrm{a} \leq \mathrm{b} \leq \mathrm{c} \leq \mathrm{d}$

$$
\mu(x)=\left\{\begin{array}{cc}
\frac{(x-a)}{(b-a)}, & a \leq x \leq b \\
1 & b \leq x \leq c \\
\frac{(d-x)}{(d-c)}, & c \leq x \leq d \\
0 & \text { otherwise }
\end{array}\right.
$$

The interval of confidence for the trapezoidal fuzzy number $\tilde{A}(a, b, c)$ at $\alpha$-level set is defined as :

$$
A_{\alpha}=\left(a_{L}^{\alpha}, a_{R}^{\alpha}\right)=[(b-a) \alpha+a, d-(d-c) \alpha],, \forall \alpha \in[0,1]
$$




\section{F. Arithmetic Operations on Fuzzy Numbers:}

In this section the researcher introduces the basic arithmetic operations on fuzzy numbers.

1.Addition and Subtraction of two Triangular fuzzy numbers:

$$
\begin{aligned}
\tilde{A}+\tilde{B} & =(a+b+c)+(d+e+f)=(a+d, b+e, c+f) \\
\tilde{A}-\tilde{B} & =(a-b-c)+(d-e-f)=(a-f, b-e, c-d)
\end{aligned}
$$

2.Addition and Subtraction of two Trapezoidal fuzzy numbers :

$$
\begin{aligned}
& \tilde{A}+\tilde{B}=(a+b+c+d)+(e+f+g+h)=(a+e, b+f, c+g, d+h) \\
& \tilde{A}-\tilde{B}=(a-b-c-d)+(e-f-g-h)=(a-h, b-g, c-f, d-e)
\end{aligned}
$$

\section{G. Defuzzification:}

Defuzzification is the process of finding crisp value which represents the average value of the TFNs. Defuzzification is a method for constructing an incontrovertible outcome in fuzzy logic, given the fuzzy sets and the equivalent degree of membership functions.

H. Robust Ranking Technique:

Robust's ranking technique which satisfy compensation, linearity, and additively properties and provides results which are consist human intuition. If ã is a fuzzy number then the Robust Ranking is defined by

$$
R(\tilde{a})=\int_{0}^{1} 0.5\left(a_{L}^{\alpha}, a_{R}^{\alpha}\right) d \alpha
$$

where $\left(a_{L}^{\alpha}, a_{R}^{\alpha}\right)$ is the $\alpha$-level cut of fuzzy number $\tilde{a}$

The Robust's Ranking technique for triangular fuzzy number is :

$$
R(\tilde{a})=\int_{0}^{1} 0.5[(b-a) \alpha+a, c-(c-b) \alpha] d \alpha
$$

The Robust's Ranking technique for trapezoidal fuzzy number is :

$$
R(\tilde{a})=\int_{0}^{1} 0.5[(b-a) \alpha+a, d-(d-c) \alpha] d \alpha
$$

This method is for Ranking the objective values. The Robust ranking index $R(\tilde{a})$ gives the representative value of fuzzy number ã.

\section{Problem Formulation}

\section{A.Assignment Problem :}

The Assignment problem (AP) can be stated in the form of $\mathrm{n} \times \mathrm{n}$ cost matrix $\left(C_{i j}\right)_{n x n}$ of real numbers as given in table 1 
Table 1. Assignment cost

\begin{tabular}{|l|l|l|l|l|}
\hline $\begin{array}{l}\text { Job } \rightarrow \\
\text { Person } \downarrow\end{array}$ & $\begin{array}{l}\text { Job } \\
1\end{array}$ & $\begin{array}{l}\text { Job } \\
2\end{array}$ & $\begin{array}{l}\text { Job } \\
k\end{array}$ & $\begin{array}{l}\text { Job } \\
n\end{array}$ \\
\hline Person 1 & $\mathrm{C}_{11}$ & $\mathrm{C}_{12}$ & $\mathrm{C}_{1 \mathrm{k}}$ & $\mathrm{C}_{1 \mathrm{n}}$ \\
\hline Person $k$ & $\mathrm{C}_{\mathrm{k} 1}$ & $\mathrm{C}_{\mathrm{k} 2}$ & $\mathrm{C}_{\mathrm{kk}}$ & $\mathrm{c}_{\mathrm{kn}}$ \\
\hline Person $n$ & $\mathrm{C}_{\mathrm{n} 1}$ & $\mathrm{C}_{\mathrm{n} 2}$ & $\mathrm{c}_{\mathrm{nk}}$ & $\mathrm{c}_{\mathrm{nn}}$ \\
\hline
\end{tabular}

Mathematically assignment problem can be stated as:

$$
\operatorname{Min} Z=\sum_{i=1}^{i=n} \sum_{j=1}^{j=n} c_{i j} x_{i j}
$$

Subject to :

$$
(A P)= \begin{cases}\sum_{i=1}^{i=n} x_{i j}=1, & j=1,2, \ldots \ldots \ldots \ldots n \\ j=n & i=1,2, \ldots \ldots \ldots \ldots n\end{cases}
$$

where $x_{i j}=\left\{\begin{array}{c}1, \text { if the } i^{\text {th }} \text { person assign the } j^{\text {th }} \text { job } \\ 0, \text { otherwise }\end{array}\right.$

Suppose there are $n$ jobs to be performed and $n$ persons are available for doing these jobs. Assume that each person can do one job at a time and each job can be assigned to one person only.

\section{B.Fuzzy Assignment Problem:}

Let $\tilde{C^{2}} i j$ be the triangular fuzzy numbers cost (payment) if $j$ th job is assigned to $p t h$ person (see table). The problem is to find an assignment $x i j$ so that the total cost for performing all the jobs is minimum.

Table 2. Fuzzy Assignment cost

\begin{tabular}{|l|l|l|l|l|}
\hline $\begin{array}{l}\text { Job } \rightarrow \\
\text { Person } \downarrow\end{array}$ & $\begin{array}{l}\text { Job } \\
1\end{array}$ & $\begin{array}{l}\text { Job } \\
2\end{array}$ & $\begin{array}{l}\text { Job } \\
k\end{array}$ & $\begin{array}{l}\text { Job } \\
n\end{array}$ \\
\hline Person 1 & $\widetilde{C_{11}}$ & $\widetilde{C_{12}}$ & $\widetilde{C_{1 k}}$ & $\widetilde{C_{1 n}}$ \\
\hline Person $k$ & $\widetilde{C_{k 1}}$ & $\widetilde{C_{k 2}}$ & $\widetilde{C_{k k}}$ & $\widetilde{C_{k n}}$ \\
\hline Person $n$ & $\widetilde{C_{n 1}}$ & $\widetilde{C_{n 2}}$ & $\widetilde{C_{n k}}$ & $\widetilde{C_{n n}}$ \\
\hline
\end{tabular}


The chosen Fuzzy Assignment Problem (FAP) may be formulated into the following fuzzy linear programming problem:

$$
\operatorname{Min} Z=\sum_{i=1}^{i=n} \sum_{j=1}^{j=n} \widetilde{C_{l j}} x_{i j}
$$

Subject to :

$$
(A P)= \begin{cases}\sum_{i=1}^{i=n} x_{i j}=1, & j=1,2, \ldots \ldots \ldots \ldots n \\ j=n & i=1,2, \ldots \ldots \ldots \ldots n \\ \sum_{j=1} x_{i j}=1 & \end{cases}
$$

where $x_{i j}=\left\{\begin{array}{c}1, \text { if the } i^{\text {th }} \text { person assign the } j^{\text {th }} \text { job } \\ 0, \text { otherwise }\end{array}\right.$

\section{III.ALGORITHM}

\section{A.Algorithm for Assignment Problem using Modified Best Candidate Method:}

This method is based on determination of the best candidates then elimination the unwanted one in order to minimize the number of solution combinations to decide the optimal solution [Hlayel (2012)]. However, notice that the solution approach using this method as one of LAP methods is divide into two phases. We will describe each phase and clarify the new modifications. The first Phase, is to elect the best candidates through choosing the prime candidate and its alternative in each row depending on the objective function (maximum or minimum value) then elect one candidate for the columns that have no candidate. There are no new modifications in this phase and the solution findings steps are as follows:

Step1: Prepare the matrix. If the matrix is unbalanced, we balance it and we would not use the added row or column candidates in our solution process.

Step2: Determination of the best candidate, it is used for minimization problems (minimum cost) or maximization problem (maximum profit): Elect the best two candidates in each row, if the candidate repeated more than one times elect it also. Check the columns that not have candidates and elect one candidate from them, if the candidate repeated more than one time elect it also.

The second phase, will introduce the following steps:

a. At the end of phase one an index matrix is produced that shows the position for each candidate.

b. Find the direct combinations and calculating the cost for each.

c. Check the unused candidates, by finding the possible candidates for them then calculate the cost for each.

d. Find the optimal solution according to the objective function.

B.Algorithm to solve fuzzy assignment problem with Modified BCM:

Step 1: First test whether the given fuzzy cost matrix of an fuzzy assignment problem is a balanced/unbalanced. If not change this unbalanced assignment problem by adding the dummy 
row (s) / column(s) and the values for the entries are zero. If it is a balanced one then go to step 2. If it is an unbalanced one then convert it into a balanced one and then go to step 2 .

Step 2: Replace the cost matrix $\mathrm{Cij}$ with linguistic variables by triangular or trapezoidal fuzzy numbers.

Step 3: Defuzzify the fuzzy cost by using Robust's ranking method

Step 4: Replace Triangular or Trapezoidal numbers by their respective ranking indices.

Step 5: Apply Modified BCM to determine the best combination to produce the lowest total weight of the costs, where elect the best two candidates in each row, if the candidate repeated more than one times elect it also. Check the columns that not have candidates and elect one candidate from them, if repeated more than once elect them.

Step 6: Construct an index matrix and find the direct combination. Calculate cost for each combination. Check for unused candidates, find the possible candidates for them and calculate cost for them also. Now find optimal solution from all the combinations.

\section{ILLUSTRATIONS}

To illustrate the proposed method a fuzzy assignment problem is solved by using the proposed method.

Example 5.1: Three persons are available to do three different jobs. From past records, the cost (in dollars) that each person takes to do each job is known and is represented by triangular fuzzy numbers and is shown in following.

Fuzzy costs (in dollars)

\begin{tabular}{|l|l|l|l|}
\hline $\begin{array}{l}\text { Person } \rightarrow \\
\text { Job } \downarrow\end{array}$ & A & B & C \\
\hline 1 & $(1,5,9)$ & $(8,9,10)$ & $(2,3,4)$ \\
\hline 2 & $(7,8,9)$ & $(6,7,8)$ & $(6,8,10)$ \\
\hline 3 & $(5,6,7)$ & $(6,10,14)$ & $(10,12,14)$ \\
\hline
\end{tabular}

Find the assignment of persons to jobs that will minimize the total fuzzy cost.

\section{Solution:}

In Conformation to model the fuzzy assignment problem can be formulated as:

$$
\begin{aligned}
& \operatorname{Min}\left\{\mathrm{R}(1,5,9) \mathrm{x}_{11}+\mathrm{R}(8,9,10) \mathrm{x}_{12}+\mathrm{R}(2,3,4) \mathrm{x}_{13}+\mathrm{R}(7,8,9) \mathrm{x}_{21}+\mathrm{R}(6,7,8) \mathrm{x}_{22}+\right. \\
& \left.\mathrm{x}_{23}+\mathrm{R}(5,6,7) \mathrm{x}_{31}+\mathrm{R}(6,10,14) \mathrm{x}_{32}+\mathrm{R}(10,12,14) \mathrm{x}_{33}\right\}
\end{aligned}
$$

Subject to

$$
\begin{gathered}
x_{11}+x_{12}+x_{13}=1 \\
x_{21}+x_{22}+x_{23}=1 \\
\\
x_{31}+x_{32}+x_{33}=1
\end{gathered}
$$

and

$$
\begin{aligned}
& x_{11}+x_{21}+x_{31}=1 \\
& x_{12}+x_{22}+x_{32}=1 \\
& x_{13}+x_{23}+x_{33}=1
\end{aligned}
$$


where $x_{i j} \in[0,1]$

Now $\mathrm{R}(1,5,9)$ is calculated by applying Robust's ranking method. The membership function of the triangular fuzzy number $(1,5,9)$ is

$$
\mu(x)=\left\{\begin{array}{cc}
\frac{(x-1)}{(5-1)}, & 1 \leq x \leq 5 \\
\frac{(9-x)}{(9-5)}, & 5 \leq x \leq 9 \\
0 & \text { otherwise }
\end{array}\right.
$$

The $\alpha$ - cut of the fuzzy number $(1,5,9)$ is

$\left(a_{L}^{\alpha}, a_{R}^{\alpha}\right)=(b-a) \alpha+a, c-(c-b) \alpha=(4 \alpha+1,9-4 \alpha)$

for which $R\left(\tilde{a}_{11}\right)=R(1,5,9)=\int_{0}^{1} 0.5(4 \alpha+1,9-4 \alpha) d \alpha=\int_{0}^{1} 0.5(10) d \alpha=5$

therefore $R\left(\tilde{a}_{11}\right)=5$

Similarly the Robust's Ranking indices of the fuzzy cost $\mathrm{a}_{\mathrm{ij}}$ is calculated as follows:

$$
\begin{gathered}
R\left(\tilde{a}_{12}\right)=9 R\left(\tilde{a}_{13}\right)=3 R\left(\tilde{a}_{21}\right)=8 R\left(\tilde{a}_{22}\right)=7 R\left(\tilde{a}_{23}\right)=8 \\
R\left(\tilde{a}_{31}\right)=6 R\left(\tilde{a}_{32}\right)=10 R\left(\tilde{a}_{33}\right)=12
\end{gathered}
$$

Replacing these values for their corresponding $\mathrm{a}_{\mathrm{ij}}$ in which result in a convenient assignment problem in the linear programming problem.

$$
\left[\begin{array}{ccc}
5 & 9 & 3 \\
8 & 7 & 8 \\
6 & 10 & 12
\end{array}\right]
$$

Solving it by modified best candidate method to get the following optimal solution.

Phase 1 :Elect Candidates

Step 1:The matrix is Balanced, where the number of rows is equal to the number of columns as shown in table 1 .

Table 1:Person-Job assignment Profit matrix after balance

\begin{tabular}{|l|l|l|l|}
\hline & A & B & C \\
\hline $\mathbf{1}$ & 5 & 9 & 3 \\
\hline $\mathbf{2}$ & 8 & 7 & 8 \\
\hline $\mathbf{3}$ & 6 & 10 & 12 \\
\hline
\end{tabular}

Step 2 : Elect the best Candidates as shown in table 2

Table 2: Best Candidates Determination Matrix

\begin{tabular}{|l|l|l|l|}
\hline & A & B & C \\
\hline $\mathbf{1}$ & 5 & 9 & 3 \\
\hline $\mathbf{2}$ & 8 & 7 & 8 \\
\hline 3 & 6 & 10 & 12 \\
\hline
\end{tabular}


Phase 2 : Obtain the BCM Combinations.

a. Draw the following index matrix (Table 3 ) showing the position of each candidate Table 3 : Best Candidate Combination Position Matrix.

\begin{tabular}{|l|l|l|l|}
\hline & A & B & C \\
\hline $\mathbf{1}$ & A1 & A2 & - \\
\hline $\mathbf{2}$ & B1 & - & B3 \\
\hline $\mathbf{3}$ & - & C2 & C3 \\
\hline
\end{tabular}

From the above table we obtain the solution set $\{\mathrm{A} 1, \mathrm{~A} 2, \mathrm{~B} 1, \mathrm{~B} 3, \mathrm{C} 2, \mathrm{C} 3\}$.

b. The direct combinations for all the candidates from the solution set and calculate the cost for each:

Combination $1:\{\mathrm{A} 1, \mathrm{C} 2, \mathrm{~B} 3\}=5+8+10=23$

Combination $2:\{\mathrm{B} 1, \mathrm{~A} 2, \mathrm{C} 3\}=9+8+12=29$

c. No unused candidate in this cost matrix so go to next step

d. The optimal solution for the given objective function (maximum of minimum cost) is determined:

In this Example its Combination 2 (Modified BCM solution).

\section{Person $1 \rightarrow$ Machine 2 \\ Person $2 \rightarrow$ Machine 1 \\ Person 3 $\rightarrow$ Machine 3}

\section{Example 5.2:}

Consider a Fuzzy Assignment problem with rows representing to a person A1, A2, A3, A4 and columns represents to the jobs B1, B2, $\mathrm{B} 3, \mathrm{~B} 4$. The cost matrix $\mathrm{C}^{\sim} \mathrm{ij}$ is given then whose elements are trapezoidal fuzzy numbers. In this problem discover the assignment of person to jobs that will minimize the aggregate fuzzy cost. Find the optimal assignment so that the total cost of job assignment becomes minimum.

\begin{tabular}{|l|l|l|l|l|}
\hline & $B 1$ & $B_{2}$ & $B_{3}$ & $B_{4}$ \\
\hline$A_{1}$ & $\begin{array}{l}(2,3,5, \\
6)\end{array}$ & $\begin{array}{l}(6,4,2, \\
0)\end{array}$ & $\begin{array}{l}(7,8,8, \\
10,11)\end{array}$ & $\begin{array}{l}(3,5,5, \\
7)\end{array}$ \\
\hline$A_{2}$ & $\begin{array}{l}(7,8, \\
10,11)\end{array}$ & $\begin{array}{l}4,9,6, \\
5)\end{array}$ & $\begin{array}{l}(6,9,4, \\
1)\end{array}$ & $\begin{array}{l}(5,8,9, \\
10)\end{array}$ \\
\hline$A_{3}$ & $\begin{array}{l}(15,10, \\
5,4)\end{array}$ & $\begin{array}{l}(5,8, \\
11,12)\end{array}$ & $\begin{array}{l}(7,6,6, \\
5)\end{array}$ & $\begin{array}{l}(6,9,4, \\
1)\end{array}$ \\
\hline$A_{4}$ & $\begin{array}{l}(1,2,4, \\
5)\end{array}$ & $\begin{array}{l}(1,4,9, \\
16)\end{array}$ & $\begin{array}{l}(8,5,1, \\
6)\end{array}$ & $\begin{array}{l}(6,8, \\
10,12)\end{array}$ \\
\hline
\end{tabular}

\section{Solution:}

The formulation of fuzzy assignment problem is,

$\operatorname{Min}\left\{\mathrm{R}(2,3,5,6) \mathrm{x}_{11}+\mathrm{R}(6,4,2,0) \mathrm{x}_{12}+\mathrm{R}(7,8,10,11) \mathrm{x}_{13}+\mathrm{R}(3,5,5,7) \mathrm{x}_{14}+\right.$ $\mathrm{R}(7,8,10,11) \mathrm{x}_{21}+\mathrm{R}(4,9,6,5) \mathrm{x}_{22}+\mathrm{R}(6,9,4,1) \mathrm{x}_{23}+\mathrm{R}(5,8,9,10) \mathrm{x}_{24}+\mathrm{R}(15,10,5,4) \mathrm{x}_{31}+$ $\mathrm{R}(5,8,11,12) \mathrm{x}_{32}+\mathrm{R}(7,6,6,5) \mathrm{x}_{33}+\mathrm{R}(6,9,4,1) \mathrm{x}_{34}+\mathrm{R}(1,2,4,5) \mathrm{x}_{41}+\mathrm{R}(1,4,9,16) \mathrm{x}_{42}+$ $\left.\mathrm{R}(8,5,1,6) \mathrm{x}_{43}+\mathrm{R}(6,8,10,12) \mathrm{x} 44\right\}$,

Subject to, 


$$
\begin{array}{ccc}
x_{11}+x_{12}+x_{13}+x_{14}=1 & , x_{11}+x_{21}+x_{31}+x_{41}=1 \\
x_{21}+x_{22}+x_{23}+x_{24}=1 & , & x_{12}+x_{22}+x_{32}+x_{42}=1 \\
x_{31}+x_{32}+x_{33}+x_{34}=1 & , & x_{13}+x_{23}+x_{33}+x_{43}=1 \\
x_{41}+x_{42}+x_{43}+x_{44}=1 & , & \\
x_{14}+x_{24}+x_{34}+x_{44}=1
\end{array}
$$

where $x_{i j} \in[0,1]$

Now the author calculate $\mathrm{R}(2,3,5,6)$ by applying Robust's ranking method. The membership function of the trapezoidal fuzzy number $(2,3,5,6)$ is

$$
\mu(x)=\left\{\begin{array}{cc}
\frac{(x-2)}{(3-2)}, & 2 \leq x \leq 3 \\
1 & 3 \leq x \leq 5 \\
\frac{(6-x)}{(6-5)}, & 5 \leq x \leq 6 \\
0 & \text { otherwise }
\end{array}\right.
$$

The $\alpha$ - cut of the fuzzy number $(1,5,9)$ is

$$
\begin{aligned}
& \left(a_{L}^{\alpha}, a_{R}^{\alpha}\right)=[(b-a) \alpha+a, d-(d-c) \alpha] \\
& \quad=[(3-2) \alpha+2,6-(6-5) \alpha]=(\alpha+2,6-\alpha)
\end{aligned}
$$

for which

$$
\begin{array}{llll}
R\left(\tilde{a}_{11}\right)=R(2,3,5,6)=\int_{0}^{1}(0.5)(\alpha+2,6- & \alpha) d \alpha=4 & \\
R\left(\tilde{a}_{12}\right)=3, & R\left(\tilde{a}_{13}\right)=9, & R\left(\tilde{a}_{13}\right)=5, R\left(\tilde{a}_{21}\right)=9, & R\left(\tilde{a}_{22}\right)=6 \\
R\left(\tilde{a}_{23}\right)=5, \quad & R\left(\tilde{a}_{24}\right)=8, & R\left(\tilde{a}_{31}\right)=8, R\left(\tilde{a}_{32}\right)=9, & R\left(\tilde{a}_{33}\right)=6 \\
R\left(\tilde{a}_{34}\right)=5, \quad & R\left(\tilde{a}_{41}\right)=3, & R\left(\tilde{a}_{42}\right)=15, R\left(\tilde{a}_{43}\right)=5, & R\left(\tilde{a}_{44}\right)=9
\end{array}
$$

Replacing these values for their corresponding to given problem then the results in a typical assignment problem in the LPP form. by solving it, the solution is in Crisp form

\begin{tabular}{|l|l|l|l|l|}
\hline & $\mathbf{B}_{1}$ & $\mathbf{B}_{2}$ & $\mathbf{B}_{3}$ & $\mathbf{B}_{4}$ \\
\hline A1 & 4 & 3 & 9 & 5 \\
\hline A2 & 9 & 6 & 5 & 8 \\
\hline A3 & 8 & 9 & 6 & 5 \\
\hline A4 & 3 & 15 & 5 & 9 \\
\hline
\end{tabular}

It is solved by modified best candidate method to get the following optimal solution.

Phase 1 : Elect Candidates

Step 1:The matrix is Balanced, where the number of rows is equal to the number of columns as shown in table 1

Table 1:Person-Job assignment Profit matrix after balance 


\begin{tabular}{|l|l|l|l|l|}
\hline & $\mathbf{B}_{1}$ & $\mathbf{B}_{2}$ & $\mathbf{B}_{3}$ & $\mathbf{B}_{4}$ \\
\hline $\mathbf{A}_{1}$ & 4 & 3 & 9 & 5 \\
\hline $\mathbf{A}_{2}$ & 9 & 6 & 5 & 8 \\
\hline $\mathbf{A}_{3}$ & 8 & 9 & 6 & 5 \\
\hline $\mathbf{A 4}$ & 3 & 15 & 5 & 9 \\
\hline
\end{tabular}

Step 2 : Elect the best Candidates as shown in table 2

Table 2: Best Candidates Determination Matrix

\begin{tabular}{|l|l|l|l|l|}
\hline & $\mathbf{B}_{1}$ & $\mathbf{B}_{2}$ & $\mathbf{B}_{3}$ & $\mathbf{B}_{4}$ \\
\hline $\mathbf{A}_{1}$ & 4 & 3 & 9 & 5 \\
\hline $\mathbf{A}_{2}$ & 9 & 6 & 5 & 8 \\
\hline $\mathbf{A}_{3}$ & 8 & 9 & 6 & 5 \\
\hline $\mathbf{A}_{4}$ & 3 & 15 & 5 & 9 \\
\hline
\end{tabular}

Phase 2 : Obtain the BCM Combinations.

a. Draw the following index matrix (Table 3 ) showing the position of each candidate Table 3 : Best Candidate Combination Position Matrix.

\begin{tabular}{|l|l|l|l|l|}
\hline & B $_{1}$ & $\mathbf{B}_{2}$ & $\mathbf{B}_{3}$ & $\mathbf{B}_{4}$ \\
\hline $\mathbf{A}_{1}$ & - & - & A3 & A4 \\
\hline $\mathbf{A}_{2}$ & B1 & - & - & B4 \\
\hline A3 & C1 & C2 & - & \\
\hline A4 & - & D2 & - & D4 \\
\hline
\end{tabular}

From the above table we obtain the solution set $\{\mathrm{A} 3, \mathrm{~A} 4, \mathrm{~B} 1, \mathrm{~B} 4, \mathrm{C} 1, \mathrm{C} 2, \mathrm{D} 2, \mathrm{D} 4\}$.

b. The direct combinations for all the candidates from the solution set and calculate the cost for each:

Combination $1:\{\mathrm{B} 1, \mathrm{C} 2, \mathrm{~A} 3, \mathrm{D} 4\}=9+9+9+9=36$

Combination $2:\{\mathrm{C} 1, \mathrm{D} 2, \mathrm{~A} 3, \mathrm{~B} 4\}=8+15+9+8=40$

c. Check for unused candidates in the solution $\operatorname{set}\{\mathrm{A} 4\}$, then find the possible combinations and calculate cost for each: 
Combination $3:\{\mathrm{B} 1, \mathrm{C} 2, \mathrm{~A} 4\}$ then we add to them $\mathrm{D} 3$ and become $\{\mathrm{A} 4, \mathrm{~B} 1, \mathrm{C} 2, \mathrm{D} 3\}=5+9+9+5$ $=28$

Combination $4:\{C 1, D 2, A 4\}$ then we add to them B3 and become $\{A 4, B 3, C 1, D 2\}=5+5+8+15$ $=33$

d. Find the optimal solution according to the objective function (maximum of minimum cost): In our case it is combination number 2 (modified-BCM solution).

\author{
Person A3 $\rightarrow$ Job B1 \\ Person A4 $\rightarrow$ Job B2 \\ Person A1 $\rightarrow$ Job B3 \\ Person A2 $\rightarrow$ Job B4
}

\title{
$V$ Conclusion
}

In this paper, the assignment costs are considered as imprecise numbers described by triangular and trapezoidal fuzzy numbers. Moreover, the fuzzy assignment problem has been transformed into crisp assignment problem using ranking function for fuzzy costs matrix and solves it by Modified Best Candidate method.

\section{References}

[1]L.A.Zadeh, "Fuzzy Sets"

[2] Mohamed Muamer, (2020), Fuzzy Assignment Problems, Journal of Science.

[3] Kadhirvel.K, Balamurugan.K, "Method For Solving Hungarian Assignment Problems Using Triangular And Trapezoidal Fuzzy Number", International Journal of Engineering Research and Applications (IJERA), ISSN: 2248-9622, Vol. 2, Issue 5, September-October 2012, pp.399-403

[4] Pathinathan. T., Ponnivalavan. K. and Mike Dison. E.," Different Types of Fuzzy Numbers and Certain Properties", Journal of Computer and Mathematical Sciences, Vol.6(11),631-651, November 2015

[5] A.Srinivasan, G.Geetharamani, (2013), Method for solving Fuzzy Assignment Problem using Ones Assignment Method and Robust Ranking Technique, Applied Mathematical Sciences.

[6] S. Narayanamoorthy and P. Vidhya, "An Adoptable Technique to Solve Fuzzy Assignment Problem”, International Journal of Pure and Applied Mathematics, Volume 117 No. 14 2017, 199-207, ISSN: 1311-8080

[7] Abdallah A. Hlayel, Khulood Abu Maria, (2013), A New Modified Approach Using Best Candidates Method For Solving Linear Assignment Problems, International Journal of Engineering Science and Technology (IJEST) 
[8] Hlayel Abdallah Ahmad,"The Best Candidates Method for Solving Optimization Problems", Journal of Computer Science 8 (5): 711-715, 2012, ISSN 1549-3636 [9]. S. Krishna Prabha, S. Vimala, (2016), Implementation of BCM for Solving the Fuzzy Assignment Problem with Various Ranking Techniques, Asian Research Journal of Mathematics. 